\title{
PEMBUATAN NPI (5-8\% Ni) MENGGUNAKAN HOT BLAST CUPOLA FURNACE KAPASITAS 3 TON/HARI
}

\author{
Manufacturing of NPI (5-8\%Ni) Using a Hot Blast Cupola Furnace \\ Capacity 3 Tons/Day
}

\author{
FAJAR NURJAMAN ${ }^{1}$, ACHMAD SHOFI ${ }^{1}$, WIDI ASTUTI' ${ }^{1}$ dan BAMBANG SUHARNO ${ }^{2}$ \\ ${ }^{1}$ UPT Balai Penelitian Teknologi Mineral-LIPI \\ J. Ir. Sutami km. 15 Tanjung Bintang 35361 Lampung Selatan \\ Telp. (0721) 350052-55, Fax. (0721) 350056 \\ e-mail: fajar.nurjaman@lipi.go.id \\ ${ }^{2}$ Departemen Teknik Metalurgi dan Material, Universitas Indonesia, Depok \\ Kampus UI Depok 16424 Jawa Barat - Indonesia \\ Telepon : (021) 786 3510, Fax : (021) 7872350
}

\begin{abstract}
ABSTRAK
Bijih besi nikel laterit merupakan batuan mineral dengan kandungan $10-40 \% \mathrm{Fe} ; 0,8-3,5 \% \mathrm{Ni}$; dan $1-2 \% \mathrm{Cr}$, yang merupakan bahan baku untuk pembuatan Nickel Pig Iron (NPI) yang selanjutnya dapat diolah menjadi besi-baja paduan mengandung $\mathrm{Ni}$ dan $\mathrm{Cr}$. Dalam penelitian ini telah dilakukan pembuatan NPI menggunakan teknologi berinvestasi rendah, yaitu hot blast cupola furnace (tungku kupola udara panas) dengan kapasitas 3 ton NPI/hari. Proses aglomerasi bijih nikel laterit menjadi pellet komposit $(\varnothing 10-20 \mathrm{~mm})$ terlebih dahulu dilakukan sebelum dilebur ke dalam hot blast cupola furnace. Komposisi (dalam \%berat) pellet komposit adalah $85,5 \%$ bijih nikel laterit; $12,5 \%$ batubara; dan $2 \%$ bentonit. Dalam proses peleburan ditambahkan kokas (sebagai bahan bakar dan reduktor) dan batu kapur (sebagai flux) ke dalam tungku tersebut. Rasio penggunaan kokas terhadap pellet komposit adalah 0,4. Penambahan batu kapur $\left(\mathrm{CaCO}_{3}\right)$ dilakukan untuk memperoleh kondisi basisitas slag 1,0. Aditif berupa $\mathrm{MnO}_{2}(39 \% \mathrm{Mn})$ juga ditambahkan ke dalam hot blast cupola furnace. Pada proses peleburan, kondisi temperatur udara panas (hot blast) adalah $250-300{ }^{\circ} \mathrm{C}$. Dari hasil penelitian diperoleh NPI dengan kandungan 5-8\% Ni. Penambahan aditif $\mathrm{MnO}_{2}$ sebanyak $1 \%$ mampu menekan laju reduksi senyawa besi oksida sehingga mampu meningkatkan kandungan Ni dalam NPI.
\end{abstract}

Kata kunci: bijih nikel laterit, NPI, hot blast cupola furnace, kokas, batu kapur.

\begin{abstract}
Nickel laterite ore containing 10-40\% Fe; 0.8-3.5\% Ni; and 1-2\% Cr was commonly used as a raw material for Nickel Pig Iron (NPI) making process which can be processed further for steel alloy containing Ni and Cr.In this present work, the NPI making process was conducted by using low investment technology, that was a hot blast cupola furnace with the capacity 3 ton/day of NPI. The agglomeration of nickel laterite ore was conducted prior to smelting process in a hot blast cupola furnace. The composition of pellet composite (in \%wt) was $85.5 \%$ of nickel laterite ore, $12.5 \%$ of coal, and $2 \%$ of bentonite. In this smelting process, coke (as a fuel and reductor) and limestone (as a flux) were added together with pellet composite into a hot blast cupola furnace. The coke to pellet composite ratio was 0.4. The limestone was added to obtain the slag basicity of 1.0. The additive of $\mathrm{MnO}_{2}$ (containing 39\%wt Mn) was also added into the hot blast cupola furnace. The temperature of the hot blast in this smelting process was $250-300^{\circ} \mathrm{C}$. From the result, NPI having $5-8 \% \mathrm{Ni}$ was obtained. The addition of $\mathrm{MnO}_{2}$ as much as $1 \%$ could suppress the reduction of iron oxide thus it could increase the Ni content in NPI.
\end{abstract}

Keywords: nickel laterite ore, NPI, hot blast cupola furnace, coke, limestone. 


\section{PENDAHULUAN}

Bijih nikel laterit (10-40\% Fe; 0,8-3,5\% Ni, dan $1-2 \% \mathrm{Cr}$ ) ditemukan pada tempat yang relatif dangkal yaitu sekitar 15-20 meter di bawah permukaan tanah. Sekitar $70 \%-80 \%$ nikel yang ada di alam berada dalam bentuk senyawa laterit yang tersebar di daerah tropis dan subtropis, seperti Indonesia, New Caledonia, Australia, Kuba dan Philipina (Elias, 2002). Cadangan bijih nikel laterit di Indonesia diperkirakan mencapai 1.391 milyar ton atau sebesar $16 \%$ dari cadangan bijih nikel laterit di dunia (Nurhakim $d k k ., 2011$ ), atau menempati urutan kedelapan terbesar di dunia.

Bijih nikel laterit menjadi salah satu bahan baku alternatif dalam proses pembuatan besi dan baja (Sufriadin, Widodo dan Biatong, 2013). Penelitian mengenai pengolahan bijih nikel laterit menjadi logam besi mengandung nikel atau Nickel Pig Iron (NPI) telah dilakukan (Prasetyo dan Prasetyo, 2011; Solihin, 2015). China telah menggunakan $\mathrm{NPI}$, sebagai bahan baku stainless steel (8 Ni$16 \mathrm{Cr}$ ). Selain sebagai bahan baku untuk pembuatan stainless steel $(18 \mathrm{Cr}-8 \mathrm{Ni}), \mathrm{NPI}$ dengan kandungan kurang dari $5 \% \mathrm{Ni}$ dapat digunakan sebagai bahan baku untuk pembuatan baja dengan karakteristik yang spesifik. Nikel sebanyak 2-3\% dalam material baja berperan sebagai unsur paduan utama untuk menghasilkan sifat-sifat unggul, seperti; kekuatan tarik yang tinggi, ketahanan korosi atau cuaca, dan sifat mampu las yang baik, bahkan mampu memberikan sifat kriogenik, yaitu ketahanan untuk menghadapi temperatur sangat rendah.

Proses pengolahan bijih nikel laterit dengan kandungan lebih dari $1,5 \% \quad \mathrm{Ni}$ diolah menggunakan proses pyrometallurgy, sedangkan bijih nikel dengan kandungan kurang dari 1,5\% Ni perlu dilakukan proses benefisiasi terlebih dahulu sebelum diolah lebih lanjut (Zhu dkk., 2012). Beberapa jenis tungku peleburan yang umumnya digunakan untuk proses peleburan bijih nikel laterit menjadi NPI, diantaranya adalah Blast Furnace (BF), Submerged Arc Furnace (SAF), dan Rotary Kiln Electric Arc Furnace (RKEF) (Rao dkk., 2013). Blast furnace merupakan salah satu tungku peleburan yang banyak digunakan untuk melebur bijih nikel laterit menjadi NPI (von Kruger $d k k ., 2010)$, dengan volume $80-220 \mathrm{~m}^{3}$. Bahan baku yang dimasukkan ke dalam blast furnace berupa bijih nikel laterit (setelah melalui proses sintering), kokas, dan batu kapur. Kokas berperan sebagai bahan bakar dan material reduktor, sedangkan batu kapur berperan sebagai material flux). Blast furnace merupakan sebuah teknologi yang "wellproven", namun tungku peleburan tersebut membutuhkan investasi yang sangat besar (Chukwuleke $d k k$., 2009). Beberapa teknologi alternatif dengan investasi yang cukup rendah untuk mengolah bijih nikel laterit menjadi NPI telah dikembangkan, diantaranya adalah dengan menggunakan induction furnace (Yildirim dkk., 2013), serta hot blast cupola furnace (Shofi $d k k ., 2013)$.

Dalam penelitian sebelumnya (Shofi, Nurjaman dan Sumardi, 2014) telah dilakukan proses pembuatan NPI $(6,873 \% \quad \mathrm{Ni})$ menggunakan hot blast cupola furnace kapasitas 1 ton NPI/hari, rasio penggunaan kokas terhadap pellet komposit bijih nikel laterit sebesar 0,6. Dalam penelitian ini telah dilakukan proses pembuatan NPI menggunakan hot blast cupola furnace dengan kapasitas yang lebih besar dari penelitian sebelumnya, yaitu 3 ton NPI/hari dengan rasio penggunaan kokas terhadap pellet komposit sebesar 0,4. Penambahan mangan dioksida $\left(\mathrm{MnO}_{2}\right)$ sebagai aditif serta kajian tekno ekonomi terhadap proses peleburan bijih nikel laterit menjadi NPI dibahas dalam penelitian ini.

\section{METODE}

Peleburan bijih nikel laterit menjadi NPI dilakukan menggunakan hot blast cupola furnace, dengan kapasitas 3 ton NPI/hari. Udara pembakaran dalam tungku tersebut terlebih dahulu dipanaskan sebelum didistribusikan ke dalam ruang pembakaran dengan memanfaatkan panas gas buang.

Proses perpindahan panas antara gas buang dengan udara pembakaran dilakukan dengan menggunakan metal recuperator (heat exchanger) yang dipasang pada bagian atas tungku kupola tersebut. Hot blast cupola furnace dalam percobaan ini telah didaftarkan patennya dengan No. P00201508520 (Nurjaman $\left.d k k_{.}, 2015\right)$. 


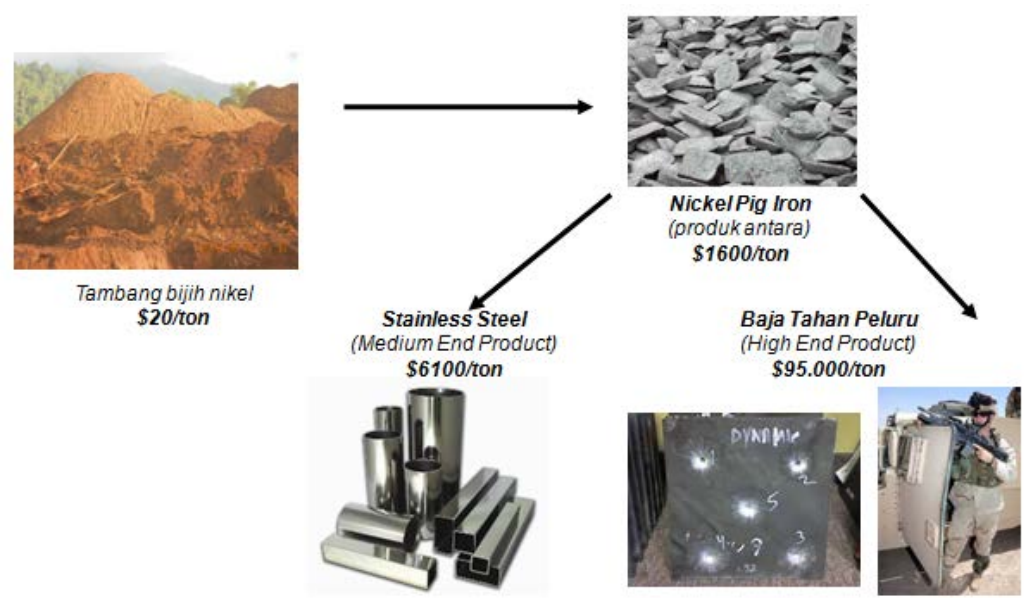

Gambar1. Peningkatan nilai tambah bijih nikel laterit menjadi produk akhir

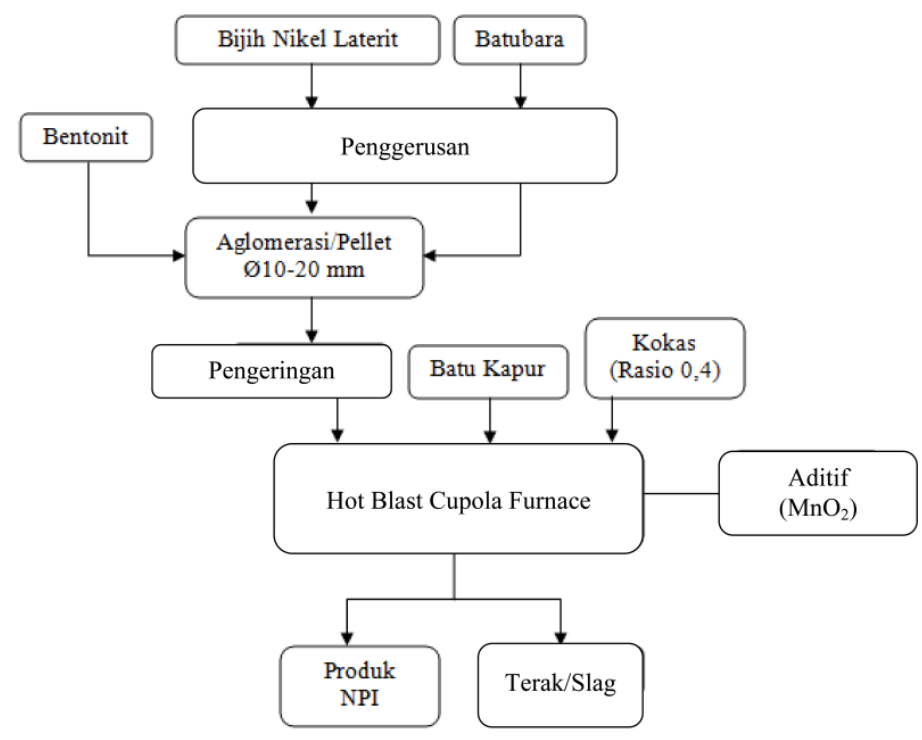

Gambar 2. Diagram alir proses peleburan bijih nikel laterit menjadi NPI

Diagram alir penelitian ditunjukkan pada Gambar 2. Sebelum dilakukan proses peleburan, terlebih dahulu dilakukan proses preparasi terhadap bijih nikel laterit. Proses penggerusan terhadap bijih nikel laterit dilakukan dengan menggunakan ball mill hingga berukuran 60-100 mesh. Selanjutnya bijih nikel laterit tersebut dicampur merata dengan batubara (sebagai material reduktor) dan bentonit (sebagai binder/perekat). Komposisi (persentase berat) dari ketiga material tersebut adalah $85,5 \%$ bijih nikel laterit; $12,5 \%$ batubara; dan $2 \%$ bentonit. Proses aglomerasi pellet dilakukan terhadap campuran ketiga material tersebut menjadi pellet komposit berukuran Ø10-20 mm, seperti tampak pada Gambar 3b, dengan menggunakan mesin pelletizer.

Tabel 1. Hasil analisis komposisi unsur dan senyawa bijih nikel laterit lokal

\begin{tabular}{cccccccc}
\hline Unsur/Senyawa & $\mathrm{Fe}$ & $\mathrm{Ni}$ & $\mathrm{Cr}$ & $\mathrm{Al}_{2} \mathrm{O}_{3}$ & $\mathrm{SiO}_{2}$ & $\mathrm{MgO}$ & $\mathrm{CaO}$ \\
\hline Kadar (\% berat) & 27,55 & 1,834 & 1,18 & 2,74 & 25,84 & 11,1 & 1,64 \\
\hline
\end{tabular}




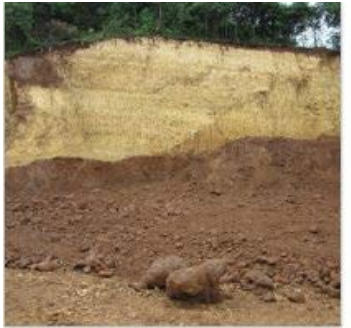

(a)
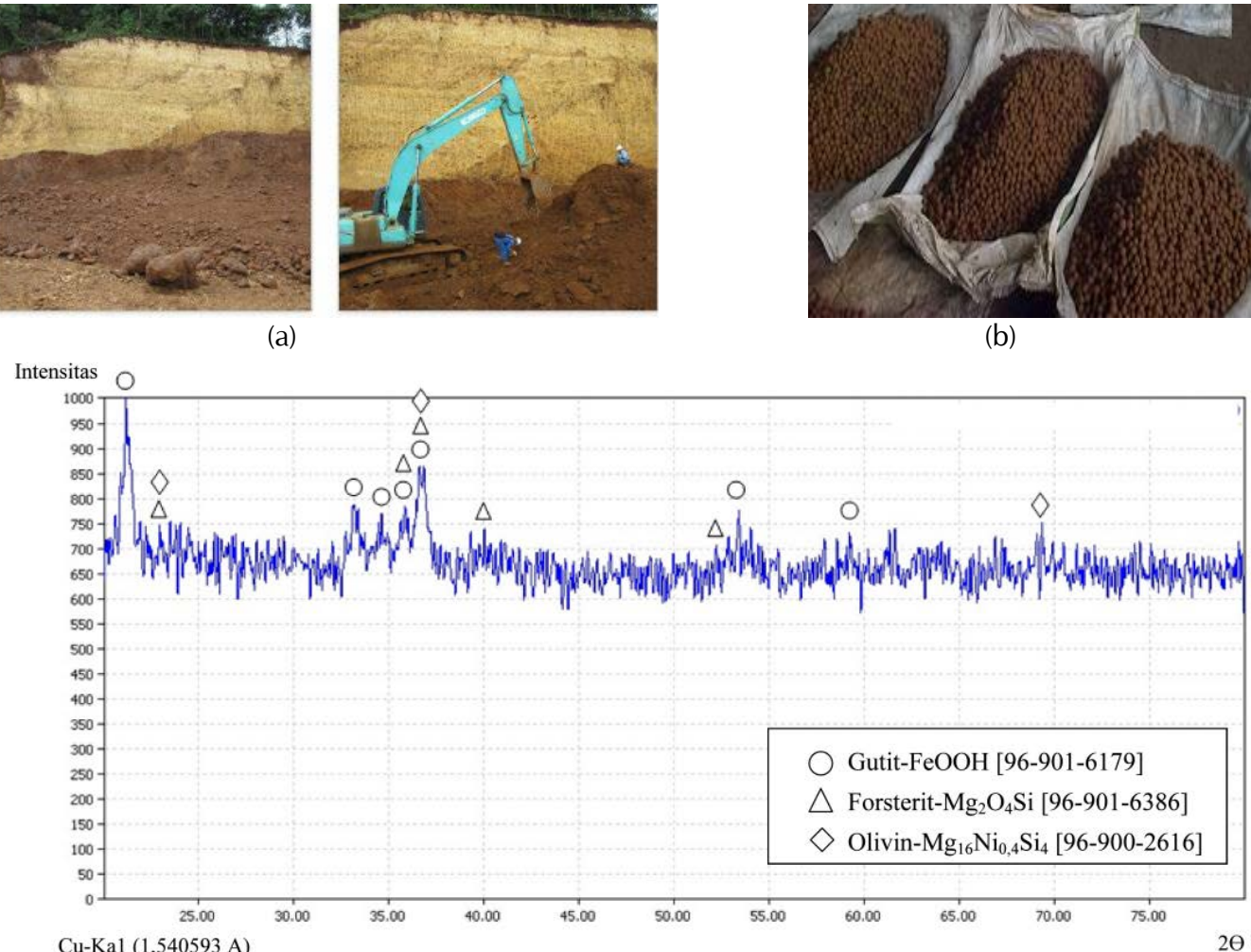

(c)

Gambar 3. (a) Bijih nikel laterit asal Torobulu, Sulawesi Tenggara; (b) pellet bijih nikel laterit; (c) hasil analisisXRD bijih nikel laterit.

Proses pengeringan dilakukan terhadap pellet komposit sebelum dimasukkan ke dalam tungku. Selanjutnya pellet komposit, bersama dengan batu kapur (sebagai flux) dan kokas (sebagai bahan bakar) dilebur dalam hot blast cupola furnace.

\section{HASIL DAN PEMBAHASAN}

\section{Karakterisasi dan Preparasi Bahan Baku Bijih Nikel Laterit}

Dalam percobaan ini terlebih dahulu dilakukan karakterisasi terhadap bijih nikel laterit lokal asal Sulawesi Tenggara sebagai bahan baku untuk pembuatan NPI, meliputi analisis komposisi unsur dan senyawa yang terkandung dalam bijih nikel laterit tersebut. Dari hasil analisis komposisi menggunakan AAS (Atomic Absorption Spectroscopy) dan XRF (X-Ray Fluroscence), pada Tabel 1, tampak bahwa bijih nikel laterit termasuk ke dalam jenis limonit dengan kandungan 1,834\% $\mathrm{Ni}$ dan $27,55 \% \mathrm{Fe}$, dengan senyawa pengotor

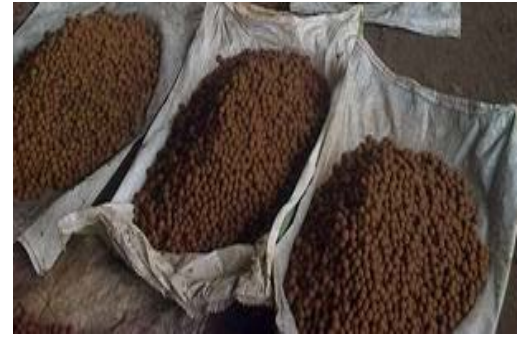

(b) 
Dalam penelitian ini, dilakukan 2 (dua) kali uji coba peleburan. Pada uji coba ke-1 dipelajari proses peleburan bijih nikel laterit menggunakan bahan bakar kokas dengan rasio kokas terhadap pellet komposit sebesar 0,4 . Sedangkan pada uji coba ke-2, dipelajari pengaruh penambahan aditif, yaitu berupa $\mathrm{MnO}_{2}$, yang bersumber dari bijih mangan, terhadap proses peleburan bijih nikel laterit menggunakan hot blast cupola furnace.
- Uji coba ke-1: rasio kokas 0,4 tanpa penambahan aditif

Pada uji coba ke-1, sebanyak $1400 \mathrm{Kg}$ pellet komposit bijih nikel laterit dilebur menjadi NPI. Tabel 2 menyajikan komposisi bahan baku peleburan bijih nikel laterit dalam hot blast cupola furnace, dan Tabel 3 menampilkan temperatur hot blast (udara panas) saat proses uji coba ke-1 berlangsung.

Tabel 2. Komposisi bahan baku uji coba ke-1

\begin{tabular}{|c|c|c|c|c|c|c|}
\hline \multirow{2}{*}{$\begin{array}{c}\text { No. } \\
\text { Umpan }\end{array}$} & \multirow{2}{*}{$\begin{array}{c}\text { Jam } \\
\text { (WIB) }\end{array}$} & Scrap & Kokas & Kapur & Pellet & \multirow{2}{*}{ Keterangan } \\
\hline & & \multicolumn{4}{|c|}{$(\mathrm{Kg})$} & \\
\hline 1 & 8.36 & \multicolumn{4}{|c|}{ Pemanasaan awal (kayu bakar) } & \\
\hline 2 & 8.45 & - & 250 & - & - & \\
\hline 3 & 10.54 & 100 & 20 & 8 & - & \\
\hline 4 & 11.58 & 100 & 20 & 8 & - & \\
\hline 5 & 12.00 & 100 & 20 & 8 & - & \\
\hline 6 & 12.01 & 80 & 25 & 8 & 20 & \\
\hline 7 & 12.03 & 80 & 25 & 8 & 20 & \\
\hline 8 & 12.05 & 60 & 30 & 15 & 40 & \\
\hline 9 & 12.07 & 60 & 30 & 15 & 40 & \\
\hline 10 & 12.12 & 40 & 40 & 23 & 60 & \\
\hline 11 & 12.32 & 40 & 40 & 23 & 60 & \multirow[t]{2}{*}{ Slag hole dibuka (deslagging-1) } \\
\hline 12 & 12.36 & 20 & 50 & 30 & 80 & \\
\hline 13 & 12.47 & 20 & 50 & 30 & 80 & \multirow[t]{8}{*}{ Tap hole dibuka (tapping-1) } \\
\hline 14 & 12.52 & - & 50 & 38 & 100 & \\
\hline 15 & 13.05 & - & 50 & 38 & 100 & \\
\hline 16 & 13.09 & - & 50 & 38 & 100 & \\
\hline 17 & 13.15 & - & 50 & 38 & 100 & \\
\hline 18 & 13.25 & - & 40 & 38 & 100 & \\
\hline 19 & 13.34 & - & 40 & 38 & 100 & \\
\hline 20 & 13.45 & - & 40 & 38 & 100 & \\
\hline 21 & 14.13 & - & 40 & 38 & 100 & \multirow[t]{3}{*}{ Slag hole dibuka (deslagging-2) } \\
\hline 22 & 14.18 & - & 40 & 38 & 100 & \\
\hline 23 & 14.25 & - & 40 & 38 & 100 & \\
\hline 24 & 15.24 & & & & & Tap hole dibuka (tapping-2) \\
\hline \multicolumn{2}{|c|}{ Total } & 664 & 1040 & 556 & 1400 & \\
\hline
\end{tabular}

Tabel 3. Kinerja hot blast uji coba ke-1

\begin{tabular}{cc}
$\begin{array}{c}\text { Jam } \\
\text { (tiap } 30 \text { menit) }\end{array}$ & $\begin{array}{c}\text { Temperatur hot blast } \\
\left({ }^{\circ} \mathrm{C}\right)\end{array}$ \\
\hline 09.03 & 30 \\
10.48 & 160 \\
10.54 & 210 \\
11.48 & 250 \\
12.08 & 200 \\
12.32 & 180 \\
13.01 & 190 \\
13.31 & 150 \\
14.00 & 220 \\
14.18 & 150 \\
15.07 & 175 \\
\hline
\end{tabular}


Seperti yang tampak pada Tabel 2, bahan baku scrap/besi (dengan kandungan 0,5-0,7\% $\mathrm{Ni)}$ juga diumpankan ke dalam hot blast cupola furnace secara bertahap, dengan rasio yang semakin berkurang terhadap pellet komposit bijih nikel laterit. Penggunaan scrap tersebut ditujukan untuk memperoleh kondisi kesetimbangan panas dalam tungku hot blast cupola furnace, sehingga pada akhirnya dimungkinkan untuk melebur umpan 100\% pellet komposit bijih nikel laterit dalam hot blast cupola furnace. Kokas, berperan sebagai bahan bakar dan reduktor, dengan rasio kokas terhadap pellet komposit pada awal pengumpanan (charging) sebesar 0,5 yang kemudian diturunkan menjadi 0,4 pada pengumpanan ke-18, seperti tampak pada Tabel 2. Penurunan rasio kokas, dari 0,5 menjadi 0,4 dalam uji coba ke-1 ditujukan untuk optimalisasi biaya konsumsi bahan bakar. Tampak pada Tabel 3, bahwa temperatur hot blast pada uji coba ke-1 adalah sebesar $150-250^{\circ} \mathrm{C}$. Temperatur hot blast cenderung menurun ketika dilakukan penurunan rasio kokas terhadap pellet komposit. Namun dari hasil uji coba ke-1, penggunaan kokas dengan rasio 0,4 (setelah pengumpanan ke-18) tidak menghambat proses peleburan yang sedang berlangsung.

Batu kapur, berfungsi sebagai pengikat kotoran/slag yang dihasilkan dari proses peleburan. Penambahan jumlah batu kapur akan memengaruhi viskositas dan temperatur titik lebur (melting point) dari slag tersebut. Dari hasil penelitian yang dilakukan oleh Li dkk. (2013) nilai basisitas slag optimum pada proses peleburan bijih nikel laterit adalah sebesar 1,0 dan nilai basisitas dinyatakan oleh persamaan (1). Oleh karena itu, dalam uji coba ke-1 ini sejumlah batu kapur (dengan kandungan $42 \%$ CaO) ditambahkan untuk memperoleh nilai basisitas slag sebesar 1,0.

$\mathrm{B}=\frac{\mathrm{CaO}+\mathrm{MgO}}{\mathrm{Al}_{2} \mathrm{O}_{3}+\mathrm{SiO}_{2}}$

Keempat umpan tersebut (scrap, kokas, pellet komposit bijih nikel laterit, dan batu kapur) dilebur dalam hot blast cupola furnace hingga mencair. Proses pengeluaran logam cair/tapping, melalui tap hole (Gambar 4a) dilakukan setelah slag dikeluarkan/deslagging terlebih dahulu, melalui slag hole dari hot blast cupola furnace (Gambar 4b).

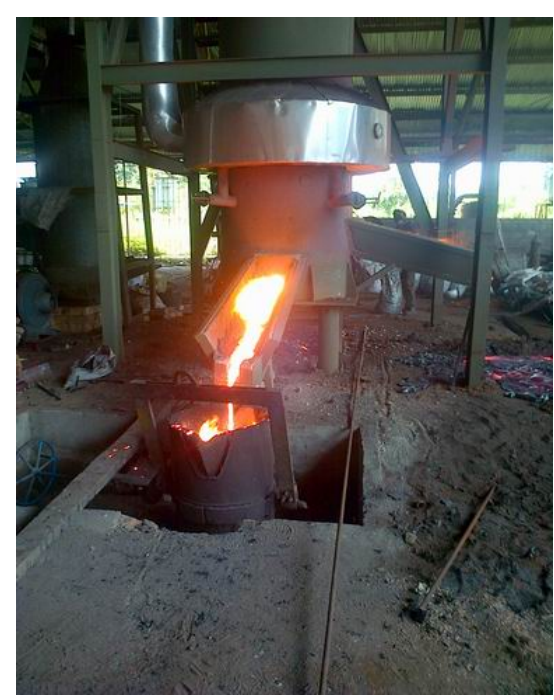

(a)

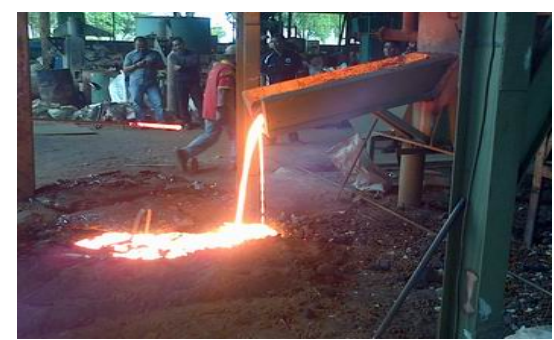

(b)

Gambar 4. Uji coba hot blast cupola furnace; (a) proses penuangan logam cair (tapping), (b) foto pengeluaran slag (deslagging)

Dari hasil uji coba ke-1, proses penuangan logam cair (tapping) dan slag (deslagging) dilakukan sebanyak dua kali. Waktu "tap to tap" dalam percobaan ini adalah 2,5-3 jam. Tabel 4 dan Tabel 5 menunjukkan komposisi dan jumlah logam dan slag pada tiap tapping dan deslagging. Adapun Gambar 5 menunjukkan hasil produk NPI tapping-2. Dari hasil uji coba ini diperoleh NPI dengan kandungan 5,3\% seperti tampak pada Tabel 4 .

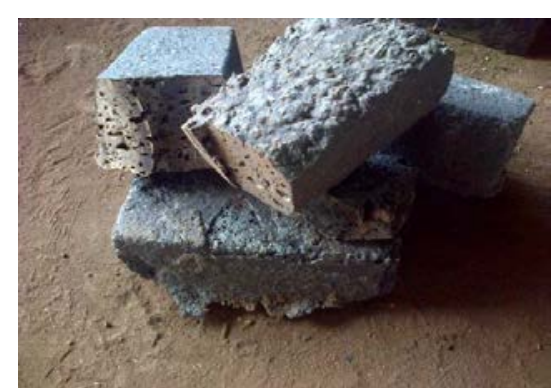

Gambar 5. NPI (5.3\%Ni) tapping-2 pada uji coba ke-1 $(5.3 \% \mathrm{Ni})$. 
Tabel 4. Komposisi produk tapping 1 dan 2 pada uji coba ke-1

\begin{tabular}{|c|c|c|c|c|c|c|c|}
\hline \multirow{2}{*}{$\begin{array}{c}\text { Tapping } \\
\text { Ke- }\end{array}$} & \multicolumn{6}{|c|}{ Unsur } & \multirow{2}{*}{$\begin{array}{c}\text { Jumlah } \\
(\mathrm{Kg})\end{array}$} \\
\hline & C & $\mathrm{Ni}$ & $\mathrm{Cr}$ & $\mathrm{Mn}$ & Si & $\mathrm{Fe}$ & \\
\hline 1 & 3,08 & 1,857 & 0,1 & 0,286 & 0,744 & 94,2 & 512 \\
\hline 2 & 2,14 & 5,3 & 1,34 & 0,423 & 0,075 & 88 & 298 \\
\hline
\end{tabular}

Tabel 5. Komposisi produk deslagging 1 dan 2 pada uji coba ke-1

\begin{tabular}{cccccc}
\hline \multirow{2}{*}{ Deslagging Ke- } & \multicolumn{4}{c}{ Unsur/Senyawa (\%) } & Jumlah \\
\cline { 2 - 5 } & $\mathrm{Ni}$ & $\mathrm{Cr}$ & $\mathrm{MnO}$ & $\mathrm{Fe}$ & $(\mathrm{Kg})$ \\
\hline 1 & 0,014 & 1,027 & 1,29 & 7,607 & 233 \\
2 & 0,035 & 1,619 & 0,035 & 8,585 & 660 \\
\hline
\end{tabular}

Dari hasil analisis slag pada Tabel 5, terdapat kandungan Fe sebesar 7-8\%, dan hanya sedikit sekali kandungan $\mathrm{Ni}$ dalam slag. Hal tersebut dikarenakan temperatur reduksi $\mathrm{Fe}$, yaitu $1200-1300^{\circ} \mathrm{C}$, jauh lebih tinggi dibandingkan dengan temperatur reduksi $\mathrm{Ni}$, yaitu $600-700{ }^{\circ} \mathrm{C}$. Dengan demikian, hot blast cupola furnace dalam percobaan ini (dengan temperatur hot blast $150-250{ }^{\circ} \mathrm{C}$ ) mampu mereduksi seluruh kandungan nikel oksida, namun sebaliknya tungku tersebut hanya mampu mereduksi $71,5 \%$ besi oksida yang terdapat dalam bijih nikel laterit.

- Uji coba ke-2: rasio kokas 0,4 dengan penambahan aditif $\mathrm{MnO}_{2}$

Pada uji coba ke-2, proses peleburan bijih nikel laterit menggunakan hot blast cupola furnace dilakukan dengan menambahkan material aditif, yaitu $\mathrm{MnO}_{2}$ yang berasal dari bijih mangan lokal (dengan kandungan 39,5\% Mn) sebanyak $1 \%$ dari total pellet komposit yang diumpankan ke dalam hot blast cupola furnace. Beberapa parameter yang digunakan dalam uji coba ke-2 menggunakan parameter yang sama telah digunakan pada uji coba ke1, diantaranya adalah: (1) jumlah rasio kokas terhadap pellet komposit sebesar 0,4, dan (2) nilai basisitas sebesar 1,0.

Tabel 6 dan 7, menunjukkan komposisi bahan baku dan temperatur hot blast selama proses uji coba ke-2 berlangsung.

Sama seperti pada uji coba ke-1, pellet komposit diumpankan secara bertahap ke dalam tungku hot blast cupola bersama dengan scrap besi (mengandung 0,5-0,7\% Ni) hingga umpan ke-13. Sebanyak $1800 \mathrm{Kg}$ pellet komposit, $700 \mathrm{Kg}$ kokas, $695 \mathrm{Kg}$ batu kapur, dan $18 \mathrm{Kg}$ bijih mangan dilebur dalam uji coba ke-2. Tampak pada Tabel 7, temperatur hot blast dalam proses peleburan adalah sebesar $140-330{ }^{\circ} \mathrm{C}$. Jumlah umpan (pellet komposit dan kokas) yang lebih banyak dibandingkan uji coba ke-1 mempengaruhi temperatur pembakaran dalam tungku hot blast cupola, sehingga meningkatkan temperatur hot blast.

Dari hasil uji coba ke-2, diperoleh NPI dengan kandungan 8,66\% Ni pada tapping-2, seperti tampak pada Tabel 8. Logam NPI yang dihasilkan tapping-2 diperoleh dari pengumpanan 100\% pellet komposit (tanpa campuran scrap). Dari Tabel 9, tampak bahwa slag pada deslagging-2 mengandung Fe yang cukup besar jika dibandingkan uji coba ke-1, yaitu $16,99 \%$ Fe. Hal tersebut disebabkan oleh keberadaan aditif berupa $\mathrm{MnO}_{2}$ yang berperan untuk menekan laju reduksi dari besi oksida yang terkandung dalam bijih nikel laterit.

Dengan semakin tingginya kandungan Fe dalam slag, maka akan meningkatkan konsentrasi nikel dalam logam NPI. Sebaliknya, penambahan aditif tidak mempengaruhi laju reduksi dari nikel oksida dalam bijih nikel laterit yang ditunjukkan dengan rendahnya kandungan nikel dalam slag. 
Tabel 6. Komposisi bahan baku uji coba ke-2

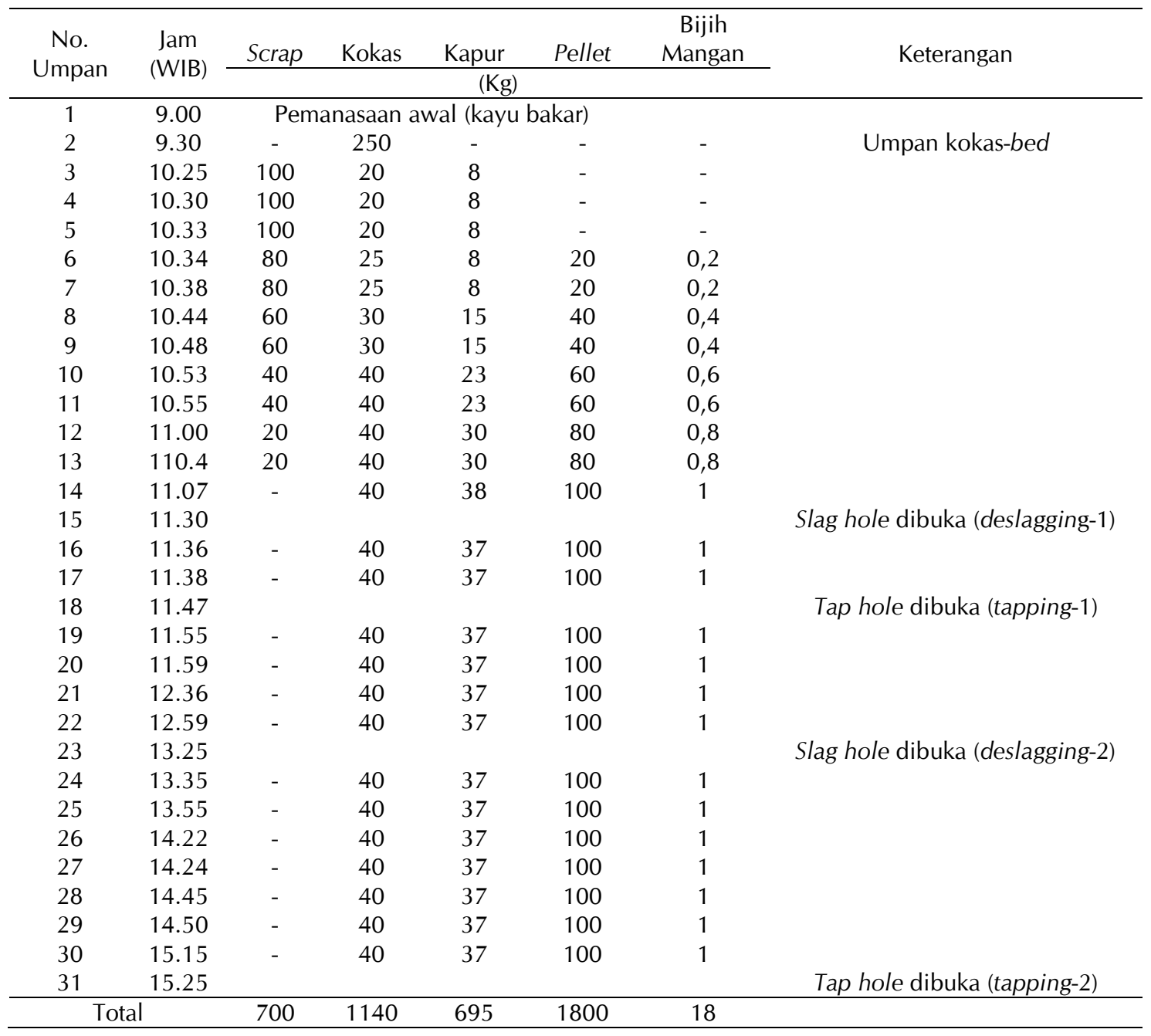

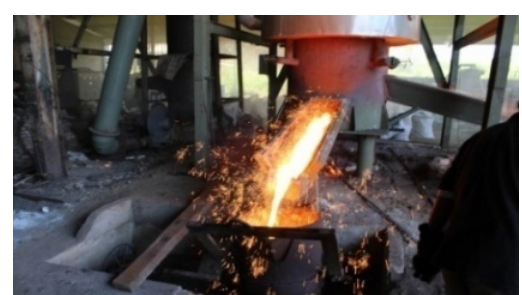

(a)

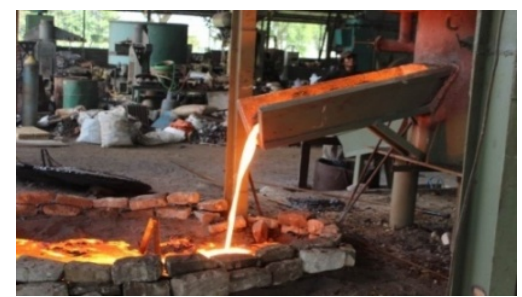

(b)
Tabel 7. Kinerja hot blast pada uji coba ke-2

\begin{tabular}{cc}
\hline $\begin{array}{c}\text { Jam } \\
\text { (tiap } 30 \text { menit) }\end{array}$ & $\begin{array}{c}\text { Temperatur } \\
\text { hot blast }\left({ }^{\circ} \mathrm{C}\right)\end{array}$ \\
\hline 09.00 & 30 \\
09.36 & 30 \\
10.03 & 100 \\
10.46 & 130 \\
10.52 & 145 \\
11.09 & 14 \\
11.30 & 110 \\
11.59 & 100 \\
12.36 & 200 \\
12.59 & 280 \\
13.30 & 300 \\
14.00 & 330 \\
14.30 & 300 \\
15.00 & 310 \\
\hline
\end{tabular}

Gambar 6. Uji coba hot blast cupola furnace; (a) proses penuangan logam cair (tapping), (b) foto pengeluaran slag (deslagging) 
Tabel 8. Komposisi produk tapping-1 dan 2 pada uji coba ke-2

\begin{tabular}{|c|c|c|c|c|c|c|c|}
\hline \multirow{2}{*}{$\begin{array}{c}\text { Tapping } \\
\text { Ke- }\end{array}$} & \multicolumn{6}{|c|}{ Unsur } & \multirow{2}{*}{$\begin{array}{c}\text { Jumlah } \\
\text { (Kg) }\end{array}$} \\
\hline & $\mathrm{C}$ & $\mathrm{Ni}$ & $\mathrm{Cr}$ & $\mathrm{Mn}$ & $\mathrm{Si}$ & $\mathrm{Fe}$ & \\
\hline 1 & 2,57 & 2,3 & 0,35 & 0,179 & 0,27 & 93,4 & 792 \\
\hline 2 & 0,5 & 8,44 & 0,07 & 0,01 & 0,03 & 90,4 & 172 \\
\hline
\end{tabular}

Tabel 9. Komposisi produk deslagging-1 dan 2 pada uji coba ke-2

\begin{tabular}{|c|c|c|c|c|c|}
\hline \multirow{2}{*}{ Deslagging Ke- } & \multicolumn{4}{|c|}{ Unsur/Senyawa (\%) } & \multirow{2}{*}{$\begin{array}{c}\text { Jumlah } \\
(\mathrm{Kg})\end{array}$} \\
\hline & $\mathrm{Ni}$ & $\mathrm{Cr}$ & $\mathrm{MnO}$ & $\mathrm{Fe}$ & \\
\hline 1 & 0,026 & 1,502 & 1,842 & 6,7 & 755 \\
\hline 2 & 0,028 & 1,31 & 1,038 & 16,99 & 454 \\
\hline
\end{tabular}

Ketentuan yang berlaku di pasar China terkait $\mathrm{NPI}$, harga NPI hanya dihitung dari kandungan nikel, sedangkan kandungan besi hanya dinilai sebagai "bonus" yang tidak diperhitungkan. Karena itu, penambahan aditif untuk menekan laju reduksi besi oksida dalam bijih nikel laterit merupakan salah satu metode "easy" dan "low cost" untuk meningkatkan kandungan Ni dalam NPI.

\section{Analisis Mass Balance}

Tabel 10 dan 11 merupakan hasil perhitungan analisis mass balance untuk uji coba peleburan ke-1 dan uji coba peleburan ke-2. Dari analisis mass balance tersebut tampak bahwa uji coba peleburan ke-2 memberikan losses $\mathrm{Ni}$ yang jauh lebih rendah jika dibandingkan dengan uji coba peleburan ke1. Hal ini menunjukkan bahwa penambahan mangan dioksida dalam proses peleburan bijih nikel laterit selain mampu menghasilkan $\mathrm{NPI}$ dengan kandungan $\mathrm{Ni}$ yang lebih tinggi juga mampu menekan losses $\mathrm{Ni}$ dalam proses peleburan.

\section{Analisis Tekno Ekonomi}

Berdasarkan Peraturan Menteri Energi dan Sumber Daya Mineral Republik Indonesia Nomor 5 Tahun 2017 tentang Peningkatan Nilai Tambah Mineral melalui Kegiatan Pengolahan dan Pemurnian Mineral di Dalam Negeri menyatakan bahwa persyaratan minimal kandungan $\mathrm{Ni}$ dalam NPI untuk diekspor ke luar negeri adalah 4\%. Oleh karena itu NPI pada tapping ke-2 dari kedua uji coba peleburan tersebut diatas telah memenuhi persyaratan minimal tersebut.

Dari hasil analisis tekno ekonomi pada Tabel 12, bahwa dari hasil uji coba ke-1, produk NPI yang dihasilkan memiliki kandungan 5,3\% $\mathrm{Ni}$, memiliki nilai ekonomis yang tidak menguntungkan. Sedangkan pada uji coba ke2 , terdapat margin/keuntungan produksi, yang diakibatkan oleh tingginya kandungan $\mathrm{Ni}$ dalam NPI, yaitu 8,33\%. Namun demikian, masih rendahnya nilai ekonomis dari uji coba kedua tersebut disebabkan oleh masih tingginya konsumsi bahan bakar (rasio 0,4), yaitu sebesar $76 \%$ dari total biaya produksi.

Tabel 10. Analisis mass balance uji coba peleburan ke-1

\begin{tabular}{lccc}
\hline \multicolumn{1}{c}{ Material Input } & Jumlah $(\mathrm{Kg})$ & $\% \mathrm{Ni}$ & Total Ni $(\mathrm{Kg})$ \\
\hline Pellet Komposit (85,5\% bijih nikel laterit) & 1400 & 1,834 & 21,95 \\
Scrap/besi & 664 & 0,7 & 4,65 \\
Total Ni input (Kg) & & & 26,60 \\
\hline \multicolumn{1}{c}{ Material Output } & Jumlah (Kg) & $\% \mathrm{Ni}$ & Total Ni $(\mathrm{Kg})$ \\
\hline NPI (tapping-1) & 512 & 1,857 & 9,51 \\
NPI (tapping-2) & 298 & 5,3 & 15,79 \\
Slag (deslagging-1) & 233 & 0,014 & 0,03 \\
Slag (deslagging-2) & 660 & 0,035 & 0,23 \\
Total Ni output (Kg) & & & 25,57 \\
\hline Losses (Total Ni input-Total Ni output) $=1,03 \mathrm{Kg}$ & & & \\
\hline
\end{tabular}


Tabel 11. Analisis mass balance uji coba peleburan ke-2

\begin{tabular}{lccc}
\hline Material Input & Jumlah $(\mathrm{Kg})$ & $\% \mathrm{Ni}$ & Total Ni $(\mathrm{Kg})$ \\
\hline Pellet Komposit (85,5\% bijih nikel laterit) & 1800 & 1,834 & 28,23 \\
Scrap/besi & 700 & 0,7 & 4,90 \\
Total Ni input (Kg) & & & 33,13 \\
\hline Material Output & Jumlah $(\mathrm{Kg})$ & $\% \mathrm{Ni}$ & Total Ni $(\mathrm{Kg})$ \\
\hline NPI (tapping-1) & 792 & 2,3 & 18,22 \\
NPI (tapping-2) & 172 & 8,44 & 14,52 \\
Slag (deslagging-1) & 755 & 0,026 & 0,20 \\
Slag (deslagging-2) & 454 & 0,028 & 0,13 \\
Total Ni output (Kg) & & & 33,06 \\
\hline Losses (Total Ni input-Total Ni output) $=0,07 \mathrm{Kg}$ & & &
\end{tabular}

Tabel 12. Analisis tekno ekonomi proses pengolahan bijih nikel laterit

(a) Uji coba ke-1

\begin{tabular}{lccc}
\hline $\begin{array}{c}\text { Bahan } \\
\text { Baku }\end{array}$ & $\begin{array}{c}\text { Volume } \\
(\mathrm{Kg})\end{array}$ & $\begin{array}{c}\text { Harga } \\
\text { Satuan } \\
(\mathrm{Rp})\end{array}$ & $\begin{array}{c}\text { Harga } \\
\text { Total } \\
(\mathrm{Rp})\end{array}$ \\
\hline Bijih nikel & 100 & 270 & 27.000 \\
kokas & 40 & 2.900 & 116.000 \\
kapur & 38 & 250 & 9.500 \\
\hline Biaya bahan baku tiap umpan & 152.500 \\
\hline Rasio NPI : bijih nikel & 7,5 \\
NPI per-umpan & 13,33 \\
Harga NPI (5,3\% Ni) * (Rp) & 7.600 \\
Total perolehan NPI (Rp) & 101.333 \\
Margin (Laba/Rugi) (Rp.) & $(51.167)$ \\
\hline Nilai ekonomis/Kg produk (Rp.) & $(3.838)$ \\
\hline
\end{tabular}

Kajian terkait optimalisasi proses peleburan bijih nikel laterit khususnya terkait efisiensi konsumsi bahan bakar (kokas) masih perlu terus dilakukan, salah satunya dengan cara meningkatkan temperatur hot blast sebelum masuk ke dalam ruang bakar.

\section{KESIMPULAN}

Nickel Pig Iron (NPI) dengan kandungan 5-8\% $\mathrm{Ni}$ dapat diperoleh dengan cara melebur pellet komposit bijih nikel laterit (27,55 Fe - 1,834 $\mathrm{Ni}$ ) menggunakan hot blast cupola furnace. Beberapa parameter dalam proses peleburan bijih nikel tersebut adalah: (1) rasio konsumsi kokas terhadap pellet komposit sebesar 0,4 dan (2) basisistas slag sebesar 1,0. Penggunaan aditif $\mathrm{MnO}_{2}$ sebanyak $1 \%$ dalam proses (b) Uji coba ke-2

\begin{tabular}{lccc}
\hline Bahan Baku & $\begin{array}{c}\text { Volume } \\
(\mathrm{Kg})\end{array}$ & $\begin{array}{c}\text { Harga } \\
\text { Satuan } \\
(\mathrm{Rp})\end{array}$ & $\begin{array}{c}\text { Harga } \\
\text { Total } \\
(\mathrm{Rp})\end{array}$ \\
\hline Bijih Nikel & 100 & 270 & 27.000 \\
kokas & 40 & 2.900 & 116.000 \\
kapur & 37 & 250 & 9.250 \\
Aditif & 1 & 500 & 500 \\
\hline Biaya bahan baku tiap umpan & 152.750 \\
\hline Rasio NPI : bijih nikel & 7,5 \\
NPI per-umpan & 13,33 \\
Harga NPI (5,3\% Ni) * (Rp) & 12.050 \\
Total perolehan NPI (Rp) & 160.627 \\
Margin (Laba/Rugi) (Rp.) & 7.877 \\
\hline Nilai ekonomis/Kg produk (Rp.) & 591 \\
\hline
\end{tabular}

peleburan pellet komposit bijih nikel laterit mampu menghambat laju reduksi besi oksida dalam pellet komposit sehingga dapat meningkatkan kandungan nikel dalam NPI.

\section{UCAPAN TERIMA KASIH}

Ucapan terima kasih ditujukan kepada Kemenristekdikti melalui program Insinas Riset Pratama Kemitraan dengan Nomor Kontrak: 04/INS-2/PPK/E/E4/2017 serta Pusat Penelitian Fisika-LIPI melalui Program Kegiatan Unggulan-LIPI, Pengembangan Material dan Rekayasa Manufaktur Tahun Anggaran 2015 (No. 934/F/2014) dan PT. Integra Mining Nusantara yang telah berkontribusi dalam pengadaan bijih nikel laterit asal Torobulu, Sulawesi Tenggara. 


\section{DAFTAR PUSTAKA}

Chukwuleke, O. P., CAI, J., Chukwujekwu, S. and XIAO, S. (2009) "Shift From Coke to Coal Using Direct Reduction Method and Challenges," Journal of Iron and Steel Research, International, 16(2), pp. 1-5. doi: 10.1016/S1006-706X(09)60018-2.

Elias, M. (2002) "Nickel laterite deposits-geological overview, resources and exploitation," in 3rd, Giant Ore Deposit Workshop. Hobart CODES Special Publication 4, pp. 205-220. Available at: https://www.researchgate.net/publication/281 422746_Nickel_laterite_deposits_geological_overview_resources_and_exploit ation.

von Kruger, P., Silva, C. A., Vieira, C. B., Araujo, F. G. S. and Seshadri, V. (2010) "Relevant aspects related to production of iron nickel alloys (pig iron containing nickel) in mini blast furnaces," in Proceedings of Ifacon XII The Twelfth International Ferroalloys Congress. Hensinki, Finland, pp. 671-680. Available at: http://www.pyrometallurgy.co.za/InfaconXII/6 71-VonKruger.pdf.

Li, G., Zhi, Q., Rao, M., Zhang, Y., Cai, W. and Jiang, T. (2013) "Effect of basicity on sintering behavior of saprolitic nickel laterite in air," Powder Technology, 249, pp. 212-219. doi: 10.1016/j.powtec.2013.08.018.

Menteri Energi dan Sumber Daya Mineral (2017) Peraturan Menteri Energi dan Sumber Daya Mineral Republik Indonesia Nomor 5 Tahun 2017 tentang Peningkatan Nilai Tambah Mineral melalui Kegiatan pengolahan dan Pemurnian Mineral di Dalam Negeri.

Nurhakim, Dwiatmoko, M. U., Romla, N. H. and Adip, M. (2011) "Identifikasi potensi endapan bijih besi laterit di bagian tengah Pulau Sebuku, Provinsi Kalimantan Selatan," InfoTeknik, 12(2), pp. 48-53. Available at: http://ppjp.unlam.ac.id/journal/index.php/info teknik/article/view/1806.

Nurjaman, F., Shofi, A., Bahfie, F., Suharno, B. and Perbawadi, L. (2015) "Metode dan alat untuk membuat nickel pig iron." Indonesia. Available http://lipi.go.id/publikasi/metode-dan-alatuntuk-membuat-nickel-pig-iron/11948.
Prasetyo, A. B. and Prasetyo, P. (2011) "Peningkatan kadar nikel (Ni) dan besi (Fe) dari bijih nikel laterit kadar rendah jenis saprolit untuk bahan baku nickel containing pig iron (NCPI/NPI)," Metalurgi (Majalah IImu dan Teknologi), 26(3), pp. 123-130. doi: 10.14203/mtl.v26i3.17.

Rao, M., Li, G., Jiang, T., Luo, J., Zhang, Y. and Fan, X. (2013) "Carbothermic reduction of nickeliferous laterite ores for nickel pig iron production in china: A Review," JOM, 65(11), pp. 1573-1583. Available at: https://link.springer.com/article/10.1007/s118 37-013-0760-7.

Shofi, A., Nurjaman, F., Astuti, W., Mufakhir, F. R. and Handoko, A. S. (2013) "Pembuatan NPI (nickel pig iron) dari bijih nikel laterit (saprolit) menggunakan tungku hot blast cupola," in Prosiding Seminar Nasional Insentif SINas Ristek, pp. 176-183.

Shofi, A., Nurjaman, F. and Sumardi, S. (2014) "Optimasi pembuatan NPI (nickel pig iron) dari bijih nikel limonit menggunakan hot blast cupola furnace," in Prosiding Seminar Nasional Insentif SINas Ristek, pp. 105-110.

Solihin, S. (2015) "Synthesis of nickel containing pig iron (NCPI) by using limonite type ore from South East Sulawesi," Jurnal RISET Geologi dan Pertambangan, 25(1), pp. 3136. doi: 10.14203/risetgeotam2015.v25.183.

Sufriadin, Widodo, S. and Biatong, R. (2013) "Karakterisasi mineralogi bijih besi laterit dan potensinya sebagai bahan baku industri besi baja di indonesia," in Prosiding Hasil Penelitian Fakultas Teknik. Universitas Hasanuddin, pp. 1-4.

Yildirim, H., Morcali, H., Turan, A. and Yucel, O. (2013) "Nickel pig iron production from lateritic nickel ores," in Proceedings of Infacon XIII - The thirteenth International Ferroalloys Congress. P. Dipner, pp. 237244. Available at: http://www.pyrometallurgy.co.za/InfaconXIII/ 0237-Yildirim.pdf.

Zhu, D. Q., Cui, Y., Vining, K., Hapugoda, S., Douglas, J., Pan, J. and Zheng, G. L. (2012) "Upgrading low nickel content laterite ores using selective reduction followed by magnetic separation," International Journal of Mineral Processing, 106-109, pp. 1-7. doi: 10.1016/j.minpro.2012.01.003 
